\title{
Atmospheric rivers impacting Northern California and their modulation by a variable climate
}

\author{
Kristen Guirguis ${ }^{1} \cdot$ Alexander Gershunov $^{1} \cdot$ Tamara Shulgina $^{1} \cdot$ Rachel E. S. Clemesha ${ }^{1} \cdot$ F. Martin Ralph ${ }^{1}$
}

Received: 12 January 2018 / Accepted: 8 November 2018 / Published online: 28 November 2018

(c) The Author(s) 2018

\begin{abstract}
Understanding the role of climate variability in modulating the behavior of land-falling atmospheric rivers (ARs) is important for seasonal and subseasonal predictability for water resource management and flood control. We examine daily activity of ARs targeting the Northern California coast over six decades using observations of synoptic-scale circulation, high-resolution precipitation, and a long-term AR detection catalog to quantify distinct types of land-falling ARs categorized by their circulation features. We demonstrate how dramatically different atmospheric states evolve into landfalling ARs along distinct pathways that are modulated by interannual (El Niño/Southern Oscillation (ENSO) and the Pacific Decadal Oscillation) and subseasonal (Arctic Oscillation, Pacific North American Pattern, Western Pacific Oscillation, and the Eastern Pacific Oscillation) modes of large-scale climate variability. Different configurations of climate variability modes are shown to favor ARs having different characteristics in terms of synoptic evolution, integrated vapor transport and landfall orientation resulting in different patterns of precipitation over the landscape. In particular, our results show that while ENSO plays an important role in modulating the synoptic evolution of ARs and their orientation at landfall, subseasonal regional climate modes, which also influence landfall orientation as well as the position of the storm track, appear to be more influential than ENSO in modulating precipitation variability in California. This could have implications for seasonal to subseasonal (S2S) forecasting. Finally, we examine AR activity over the most recent and highly anomalous winter 2016-2017 and show how the unprecedented wet conditions in Northern California were at least partly due to the persistence of ARs characterized by a southward storm track and southerly orientation, which represent the type of ARs associated with heavy rainfall in California, and which are associated with the negative phase of subseasonal regional teleconnection patterns.
\end{abstract}

\section{Introduction}

California is home to over 38 million people and counting, an extensive agriculture industry and a large diverse economy, all relying on volatile water resources derived during the cool season and stored in mountain snowpack and engineered reservoirs. The wettest winter storms are atmospheric rivers (ARs), characterized as filaments of strong moisture

Electronic supplementary material The online version of this article (https://doi.org/10.1007/s00382-018-4532-5) contains supplementary material, which is available to authorized users.

Kristen Guirguis

kguirguis@ucsd.edu

1 Climate, Atmospheric Science and Physical Oceanography (CASPO) Research Division, Center for Western Weather and Water Extremes (CW3E), Scripps Institution of Oceanography, University of California, San Diego, 9500 Gilman Drive, 92093 La Jolla, CA, USA transport (Ralph et al. 2006). These AR events are capable of transporting large amounts of moisture to California and can bring heavy precipitation, which can lead to widespread flooding (e.g. Ralph et al. 2006; Neiman et al. 2008; Leung and Qian 2009; Konrad and Dettinger 2017). They are also critical for water resources in a region where a handful of large ARs bring most of the precipitation in a given water year (Dettinger et al. 2011). This means that water storage can change dramatically from year-to-year depending on the frequency and intensity of AR events. ARs can act as drought-busters in California (Dettinger 2013), which was the case during this past winter of 2016/2017 when inordinate AR activity, unprecedented in 70 winters of record, impacted California (Gershunov et al. 2017, hereafter GSR' 17) leading to a record-breaking water year in the Northern Sierra. This type of quick recovery from drought has historically had an exceedingly low probability of occurrence (Diaz and Wahl 2015). However, dramatic transitions from drought to extreme wet conditions (so called "climate 
whiplash") may become more likely in association with long-term climate change (Swain et al. 2018).

Understanding the links between climate variability and AR activity is important for subseasonal to seasonal predictability, particularly since we expect water resources in California to become even more volatile in the future when precipitation will be delivered in fewer but more extreme storms (Polade et al. 2014, 2017). Although El Niño/Southern Oscillation (ENSO) has historically, albeit not recently, strongly modulated the probability of heavy precipitation in the western US (e.g. Gershunov 1998), ENSO influence on AR landfalling activity is less clear. GSR' 17 showed a strong relationship between ENSO and total seasonal west coastal IVT, but did not observe a significant ENSO relationship with AR activity. Guan and Waliser (2015) showed enhanced AR activity in the more northern latitudes of Western North America (Pacific Northwest, British Columbia, and Alaska) during El Niño but the converse was not observed during La Niña, and no ENSO relationship was observed in California. Kim et al. (2017) found that the Central Pacific El Niño brings higher intensity storms and more ARs to the southern Latitudes $\left(20-30^{\circ} \mathrm{N}\right)$ while during $\mathrm{La}$ Niña fewer storms reach the US west coast.

The phase of ENSO has been shown to affect the orientation of the storm track with respect to ridge and trough patterns along along the US west coast, with more anticyclonic events during La Niña years and more cyclonic events during El Niño (Favre and Gershunov 2006; Ryoo et al. 2013; Kim and Alexander 2015; Kim et al. 2017). The impinging orientation of IVT relative to local topography has been shown to be important in determining inland penetration of water vapor, the amount of precipitation, and its spatial pattern (e.g. Hu et al. 2017, GSR'17). For example, Hu et al. (2017) showed that, along the Western US, the heaviest precipitation tends to occur when vapor transport is aligned approximately perpendicular to the terrain barrier. They showed that ARs with a cyclonic orientation tend to bring more precipitation to California, while an anticyclonic orientation brings more precipitation to the Pacific Northwest. This is quite consistent with earlier reports on the spatial structure of flooding associated with ARs occurring during different ENSO phases (Ralph et al. 2003; Andrews et al. 2004).

Other teleconnection patterns have also been investigated for links to AR activity. The positive phase of the Pacific/ North American (PNA) pattern has been linked to more landfalling ARs in the Pacific Northwest while the negative phase is associated with stronger AR activity in central and southern California and offshore in northern California (Guan and Waliser 2015). The joint negative in-phase relationship between the Arctic Oscillation (AO) and PNA was found to be associated with extreme snowfall in the Sierra Nevada during the winter of 2010/2011 (Guan et al. 2013).
GSR'17 examined seven decades of landfalling AR activity along the west coast of North America and described relationships between seasonal AR-related vertically integrated vapor transport (IVT) and large-scale modes of climate variability. In particular, they found strong relationships between AR activity and the Pacific Decadal Oscillation (PDO) as well as with coastal sea surface temperature (SST) anomalies representing the northeastern Pacific "blob" described by Bond et al. (2015), which clearly contributed to an AR deficit in California and Oregon in winters 2013-2014 and 2014-2015 (GSR'17).

The recent water year 2016/2017 (WY'17) has shed light on the challenge of seasonal precipitation forecasts in California. In this paper, we investigate this recent AR activity in a historical context with the goal of providing useful information towards understanding the role of large-scale climate variability in modulating both the frequency of AR landfalls as well as in determining the properties of landfalling ARs in terms of IVT content, orientation and resulting precipitation. For example, why did WY'2017 deliver copious amounts of precipitation unexpectedly during a weak La Niña?

Figure 1 provides a brief summary of AR activity during WY' 17 in a historical context. From this figure, WY' 17 was slightly below normal in the Pacific Northwest and much above normal in California both in terms of the number of AR landfalls (Fig. 1a) and coastal IVT (Fig. 1b). The major difference between WY'17 and historical climatology was over California, particularly at latitudes $37.5-42.5^{\circ} \mathrm{N}$, which is the fulcrum of the canonical ENSO influence for precipitation in general. For this study, we focus on ARs making landfall at the coast at $40^{\circ} \mathrm{N}$, which is in the vicinity of the Russian River, near Coyote Valley Dam, Lake Mendocino. This is the region of the most vigorous AR activity (in terms of IVT intensity) in California and generally along the North American west coast (GSR'17). ARs provide approximately half of the precipitation climatologically in this region and managers who operate the State's reservoirs including Lake Mendocino who are charged with responsibilities including flood control, river species protection, public water supply, and sourcing hydroelectric power need better information about the seasonal behavior of ARs including its potential predictability.

Our approach is to identify different types of ARs impacting this important location in Northern California. We are interested in understanding the role of largescale circulation on the occurrence and characteristics of landfalling ARs. Therefore, we categorize different types of ARs according to large-scale circulation using selforganizing maps (SOM). We aim to elucidate some of the important mechanisms responsible for precipitation variability with the goal of providing insight that could be useful for improving seasonal to subseasonal (S2S) predictions of landfalling ARs. Given that the demand for water 
Fig. 1 Daily probability of a landfalling AR at different latitudes along the North American West Coast (a) and daily average IVT (b) shown for climatology (1950-2013, black) and the recent water year 2016-2017 (red)

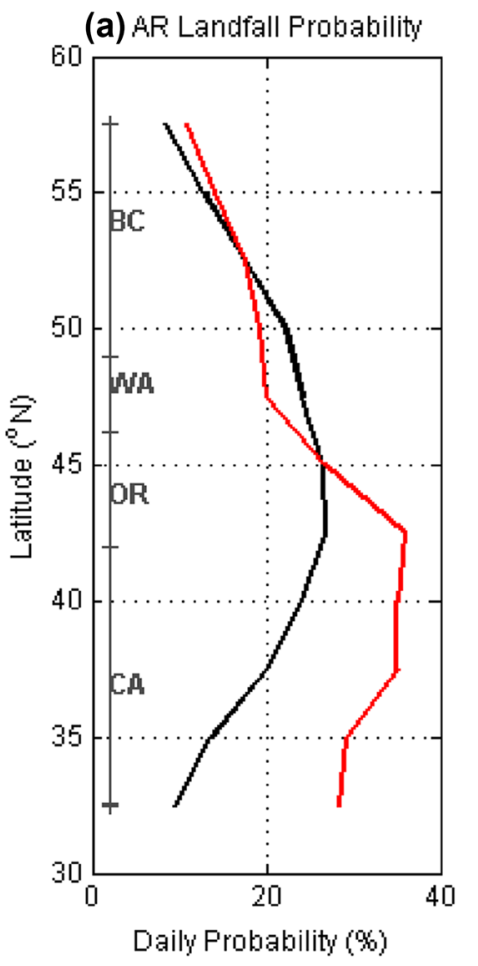

(b) Daily Average IVT

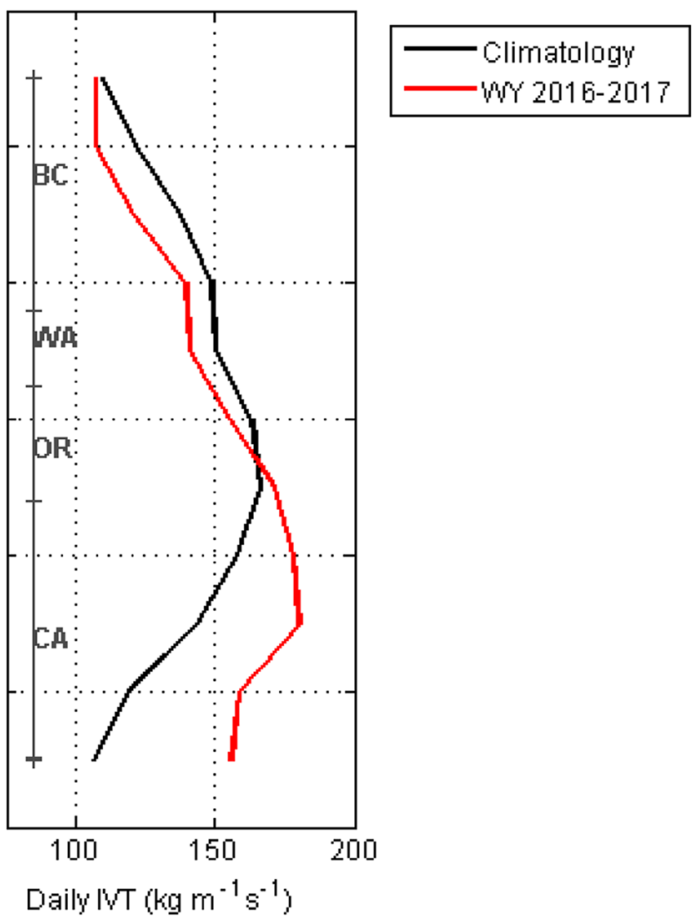

is expected to grow with rising temperatures, improving our understanding and predictability of landfalling ARs is critical for making decisions about the State's water supply.

In what follows, we first conduct a historical analysis of AR behavior and then consider WY'17 in this historical framework. We first describe the data sources and methodology in Sect. 2. Next, in Sect. 3, we identify distinct types of ARs in the historical record using self-organizing maps trained on 500-mb geopotential height anomalies and examine links between landfalling AR activity and largescale modes of climate variability. We then examine AR characteristics such as of synoptic evolution, IVT content, landfall orientation, and precipitation. In Sect. 4, we discuss the application to the most recent 2016-2017 complete water year. A summary and discussion is provided in Sect. 5.

\section{Data and methods}

\subsection{Integrated vapor transport}

Daily vertically integrated vapor transport (IVT) is calculated from wind and humidity data, which was obtained from NCEP-NCAR global Reanalysis (hereinafter R1, Kalnay et al. 1996) at 6-hourly intervals over 8 pressure levels between 1000 and $300 \mathrm{hPa}$. For this study, we use daily averages derived from the 6-hourly IVT fields. As in GSR'17, IVT here is considered as a vector field.

\subsection{Atmospheric rivers}

Historical landfalling atmospheric rivers were identified using the SIO-R1 catalog introduced and described in detail in GSR' 17. This catalog identifies ARs making landfall along the North American West Coast $\left(20^{\circ}-60^{\circ} \mathrm{N}\right)$ from 1948 to the near-present using 6-hourly IVT fields. For this study, we extracted all days when an AR was making landfall in Northern California at $40^{\circ} \mathrm{N}$ during November-February between 1950 and 2013, where the time period was chosen based on the availability of precipitation data. We then identified a list of peak days by grouping consecutive landfall days into events, and calculating the peak day as the day within each event when the maximum IVT value occurred at $40^{\circ} \mathrm{N}$. By our definition, $40^{\circ} \mathrm{N}$ does not need to be the center landfall latitude, but rather is required to be contained within the swath of the landfalling AR. An AR is identified in the SIO-R1 catalog if the 6-hourly observed IVT exceeds $250 \mathrm{~kg} \mathrm{~m}^{-1} \mathrm{~s}^{-1}$ at the landfalling location, and the IVT field meets certain geometric and continuity criteria. Our analysis uses daily averages of AR IVT at $40^{\circ} \mathrm{N}$, so if an AR was only present for part of a day then the daily average can be lower than $250 \mathrm{~kg} \mathrm{~m}^{-1} \mathrm{~s}^{-1}$.

The climatological probability for a landfalling AR at our location is $24 \%$, meaning that an AR makes landfall at $40^{\circ} \mathrm{N}$ during at least one 6-h timestep on $24 \%$ of days during 
Nov-Feb. Our analysis period was selected to span the availability of the high-resolution precipitation data (Livneh et al. 2013, available through 2013) and the most active part of the season in terms of AR activity (Nov-Feb), which at this location peaks in December. The location $40^{\circ} \mathrm{N}$ was chosen because this latitude represents the location where WY' 17 was most active and it is a point of marked difference between the recent water year and climatology in terms of AR landfalls and coastal IVT. It is also the most active region along the US west coast in terms of seasonal AR landfalling IVT intensity (GSR'17), and it is a critical location from a water resources perspective so understanding AR activity at this location is important for flood risk and water resource management (Ralph et al. 2006). In Sect. 4, we apply our historical analysis to the recent 2016-2017 water year using the SIO-R1 for November 1, 2016-February 28, 2017.

\subsection{Atmospheric circulation and wind fields}

Atmospheric circulation features and wind fields associated with landfalling ARs were analyzed using daily data from $\mathrm{R} 1$. We used $500 \mathrm{mb}$ geopotential height (G500) anomalies to identify the AR landfall-associated flavors of synoptic circulation patterns. We also used $850 \mathrm{mb}$ geopotential height fields and $850 \mathrm{mb}$ wind fields for composite analyses. Daily anomalies were obtained by filtering out the annual and semiannual harmonic seasonal cycle using least squares regression analysis.

\subsection{Precipitation}

Precipitation data are from Livneh et al. (2013), which is an observationally-based gridded product derived from daily station data interpolated to a $1 / 16^{\circ}$ latitude-longitude grid. The source data are the cooperative observer (coop) summaries of the day from the National Centers for Environmental Information supplemented by first-order automated surface observing system observations (National Climatic Data Center 2009).

\subsection{Teleconnection indices}

To identify links between ARs and large-scale climate variability modes, we used the monthly indices for ENSO and the PDO and daily indices for the AO, PNA, Western Pacific Oscillation (WPO), and Eastern Pacific Oscillation (EPO). The Niño3.4 index and the daily North American Teleconnection Indices are from the Climate Prediction Center (http://www. cpc.ncep.noaa.gov). The PDO index is from the University of Washington (http://jisao.washington.edu/pdo). For this analysis, when daily index values were needed, each day was assigned to the monthly value of PDO and ENSO to create daily ENSO and PDO indices. Composites showing the circulation anomaly patterns corresponding to the positive and negative phases of the AO, PNA, WPO, and EPO are shown in Figure S1. In the discussion, we sometimes refer to the AO, PNA, WPO, and EPO as "regional climate modes" since their teleconnection patterns are expressed in a common region. These regional modes, originally identified in Barnston and Livezey (1987), have been shown to have e-folding timescales on the order of 7-10 days (Feldstein 2000) and we therefore refer to these patterns as "subseasonal" modes.

\subsection{Self-organizing maps}

SOM analysis has been employed previously in AR studies. Swales et al. (2016) used SOMs trained on IVT fields over the western US to identify moisture pathways into the intermountain west associated with landfalling ARs. For this analysis, we applied SOM to 500-mb geopotential height anomaly fields to identify the different synoptic pathways that lead to a landfalling $\mathrm{AR}$ at $40^{\circ} \mathrm{N}$. Additionally, we are interested in the role of the regional climate modes, which are defined on 500-mb geopotential height fields and this approach allows us to investigate how the different modes interact in ways that might favor different flavors of landfalling ARs at $40^{\circ} \mathrm{N}$. The non-linear SOM methodology has advantages over other matrix methods such as Principal Components Analysis in their ability to represent the full continuum of the observed field, including patterns that may not be orthogonal (Reusch et al. 2005).

Self-organizing maps of order $3 \times 3$ were trained on standardized G500 anomaly fields for peak AR days at $40^{\circ} \mathrm{N}$. Each day of the training data is classified as belonging to a bestmatch node, and the SOM patterns represent composites of the G500 fields for each node (Fig. 2). The ARs assigned to the same node share similar properties in terms of synoptic weather conditions, and we call these different "types" of ARs.

The nine SOM patterns represent nine synoptic patterns associated with landfalling ARs at $40^{\circ} \mathrm{N}$. The organization of the SOMs is such that the maps which are closer together are more similar (e.g. 1 and 2 or 8 and 9), and the maps that are farther apart are more different (e.g. 1 and 9 or 3 and 7). Additionally, the maps on the top versus the bottom tend to differ based on latitudinal differences, whereas the maps on the left versus the right tend to differ based on zonal features. We chose to analyze nine SOMs following some preliminary analyses. We also performed the SOM analysis for a $2 \times 3$ topology, as well as for different months within the wet season and for the satellite period. The results were stable. 
Fig. 2 Self-Organizing Maps trained on G500 anomalies for peak AR days at $40^{\circ} \mathrm{N}$ along with the number of days $(\mathrm{N})$ assigned to each node
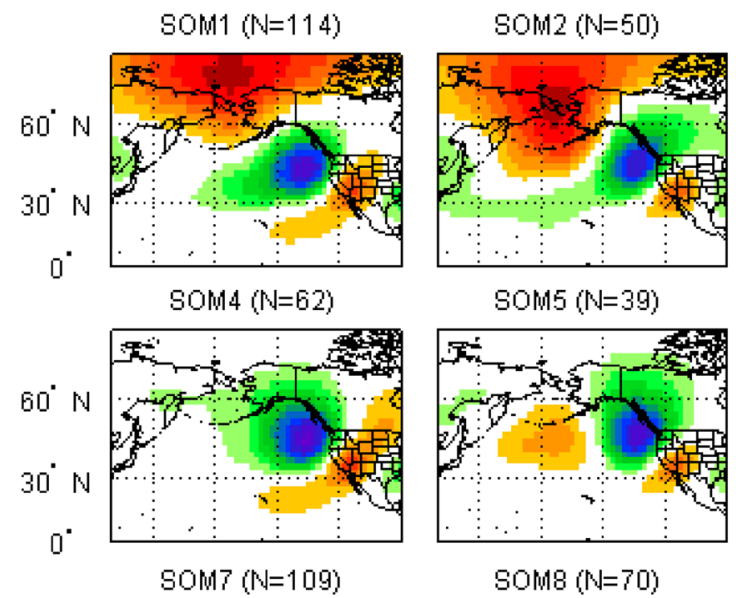

Soms (N=70)
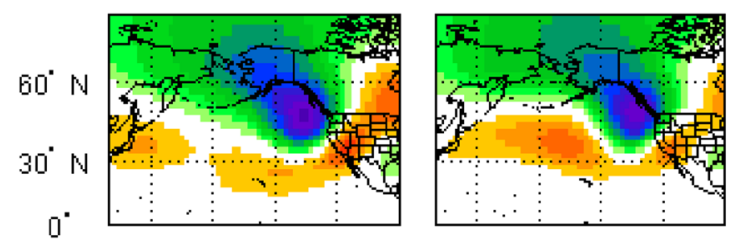

SOM3 $(\mathrm{N}=111)$

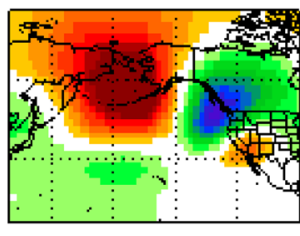

SOW6 (N=60)

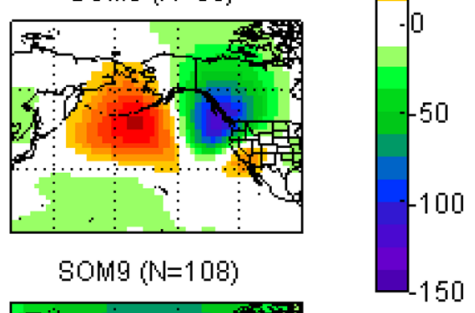

产

\section{Historical analysis}

\subsection{Landfalling ARs and associations with large-scale teleconnection patterns}

The SOM results give nine synoptic patterns associated with landfalling ARs at $40^{\circ} \mathrm{N}$, as shown in Fig. 2. The common feature among the nine nodes is the low-high pair (a low in the Gulf of Alaska offshore of British Columbia and a high positioned over the Southwest US with a gradient parallel to the coast that acts to channel moisture onshore toward Northern California). However, the details of these low-high pairs differ between nodes and represent important differences in the climate state for each type of AR. Figure 3 gives the preferred climate state for each type of AR using

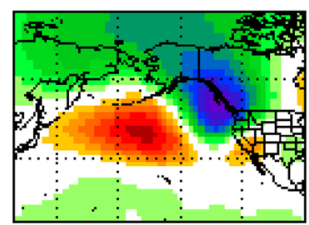

composites of the six teleconnection indices. From this figure, we see that AR types 1, 4, and 7 (left nodes) represent ARs that occurred during El Niño/PDO + while types 3, 6 and 9 (right nodes) represent ARs that made landfall during La Niña/PDO-. Also for these nodes, the PNA is generally in phase with ENSO/PDO. Comparing Figs. 2 and 3, we see that types 1-3 represent ARs occurring when the AO/WPO/ EPO are negative. Alternatively, types 7-9 represent ARs occurring when the AO/WPO/EPO are positive. The remaining nodes represented by the center column (center row) represent ARs having synoptic characteristics intermediate of the left-right (top-bottom) extremes. The joint phasing of $\mathrm{ENSO} / \mathrm{PDO} / \mathrm{PNA}$ and of AO/WPO/EPO is not necessarily indicative of AR predictability, but could represent the general climate behavior where these teleconnection patterns are more likely to be in-phase than out-of-phase. ENSO, PDO,
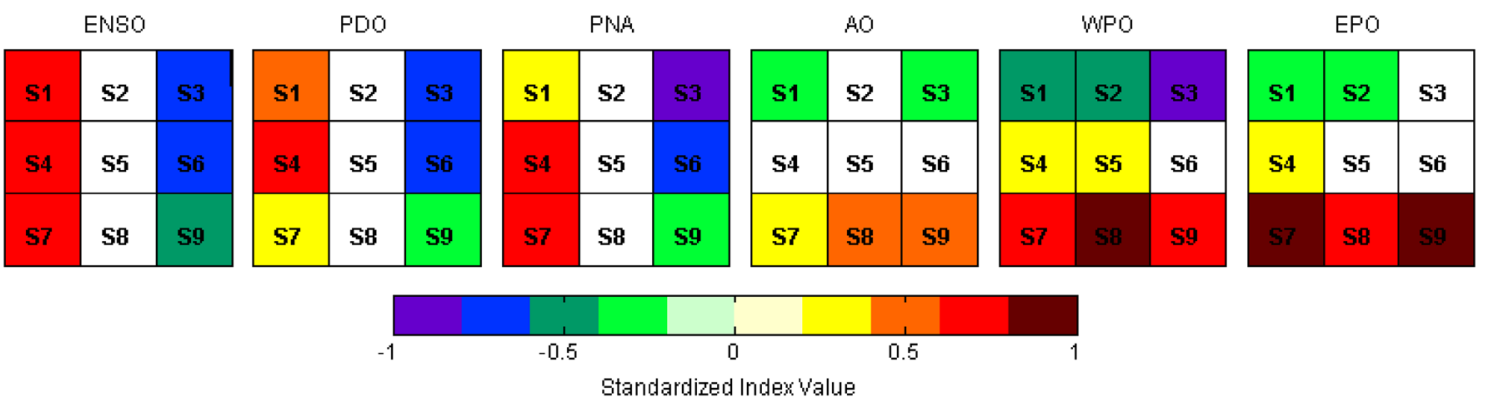

Fig. 3 Composites of the six teleconnection indices corresponding to each node in Fig. 2. Each panel represents a different teleconnection pattern (ENSO, PDO, etc.) and each box within each panel represents a node. For example, considering ENSO, the average value of the Niño 3.4 index is 0.63 for node 1 (shaded red) and the value is
-0.58 for node 9 (shaded green). The text "S1", "S2",.., "S9" represents "SOM1", "SOM2",..., "SOM9". Shading indicates that the mean index value is statistically different from climatology (t-test for unequal means, $95 \%$ confidence) 
and PNA are positively correlated as are the AO, WPO, and EPO (though not all of these correlations are particularly strong, see Figure S2). Figures 2 and 3 demonstrate how different atmospheric states associated with different configurations of climate variability modes can produce ARs having different characteristics. Below we investigate how these synoptic differences affect synoptic evolution, IVT, landfall orientation, and precipitation. In the discussion below, we treat ENSO and the PDO as one source of climate variability, given that they are part of the same teleconnection pattern (Gershunov and Cayan 2003), and are shown to be in phase in Fig. 3. Therefore, when we refer to El Niño (La Niña) in the text, the implication is that the PDO is in the positive (negative) phase, respectively, as well.

\subsection{IVT, landfall orientation, and precipitation}

Figure 4 gives composites of IVT and $850 \mathrm{mb}$ wind fields for the nine AR types. The ARs on the right (3, 6 and 9, which are associated with La Niña/PDO-, hereinafter "La Niña") exhibit a more westerly flow with wind directions nearly perpendicular to the coastline at the landfalling location.
The ARs on the left (1,4 and 7, which are associated with El Niño/PDO+, hereinafter "El Niño") show ARs making landfall in a more southwesterly direction. The difference in AR landfall characteristics during La Niña versus El Niño is explored in more detail for the coastal $40^{\circ} \mathrm{N}$ location in Fig. 5. From Fig. 5a, we see there is a significant difference ( $t$ test for unequal means, 95\% confidence) in wind direction with La Niña flow hitting land in a southwesterly-towesterly orientation (mean $=235^{\circ}$ from the meridian) and $\mathrm{El}$ Niño bringing flow that is more southerly-to-southwesterly $\left(\right.$ mean $\left.=219^{\circ}\right)$. From Fig. $5 b, c$, the IVT content and wind speed onshore is similar (with no significant difference) at $40^{\circ} \mathrm{N}$ during La Niña and El Niño conditions. However, offshore and to the north at the coast, El Niño ARs are clearly associated with higher IVT (Fig. 4).

Figure 6 shows the composite of precipitation associated with the peak AR day for all of the historical ARs making landfall at $40^{\circ} \mathrm{N}$. In general, when an AR is making landfall at $40^{\circ} \mathrm{N}$, the heaviest precipitation occurs along the coast at the California-Oregon border. Precipitation also occurs along the California Coast and over the Sierra Nevada as well as inland into Oregon. Figure S3
Fig. 4 Composites of IVT (shaded) along with $850 \mathrm{mb}$ wind fields (vectors) for the nine AR types. The text framing the perimeter describes the states of ENSO and the regional climate modes, using the findings from Fig. 3. In general, the left (right) columns correspond to El Niño (La Niña) and the top (bottom) rows correspond to the negative (positive) phase of the regional climate modes (AO/EPO/WPO)

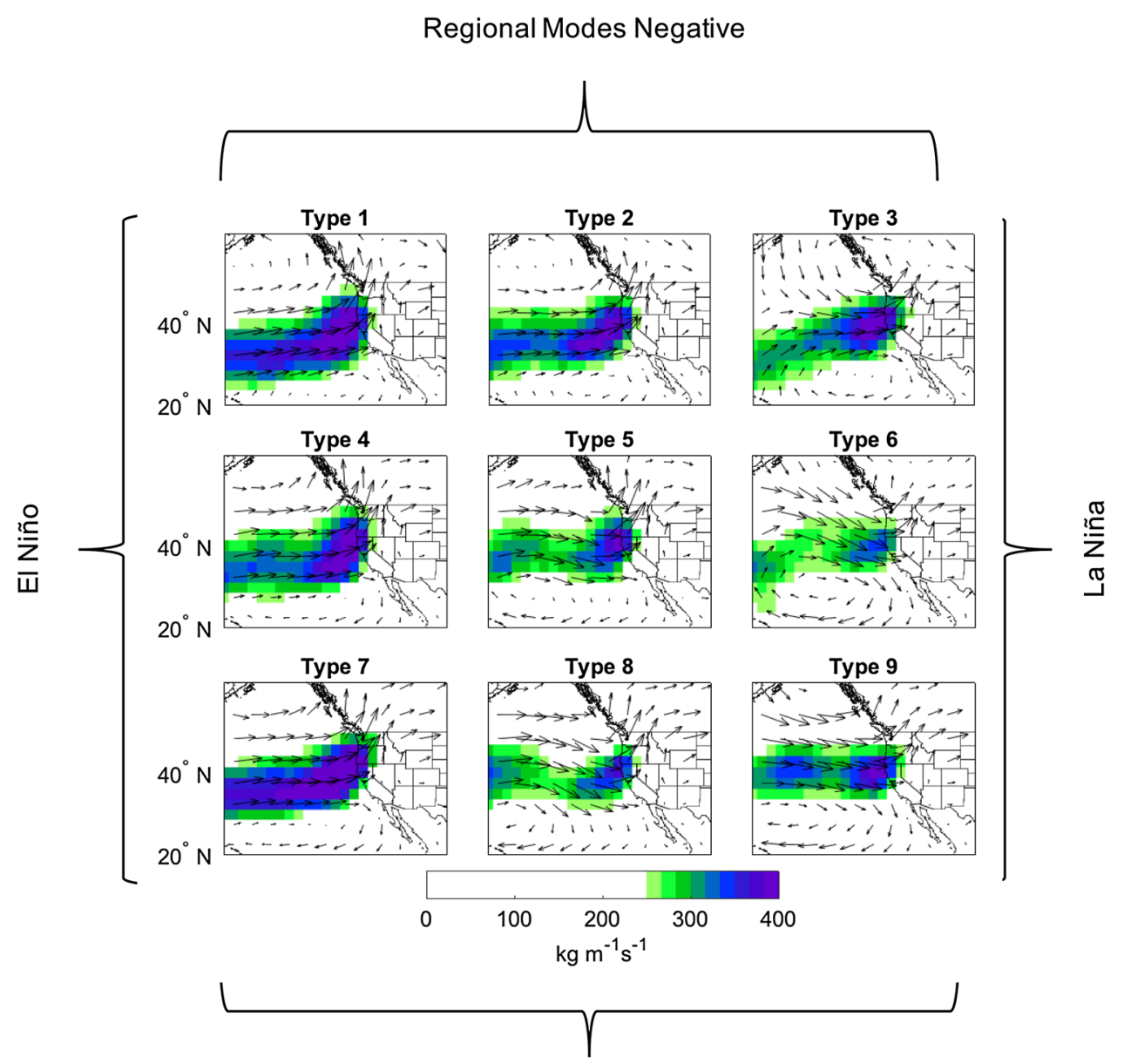

Regional Modes Positive 
(a) Wind Direction

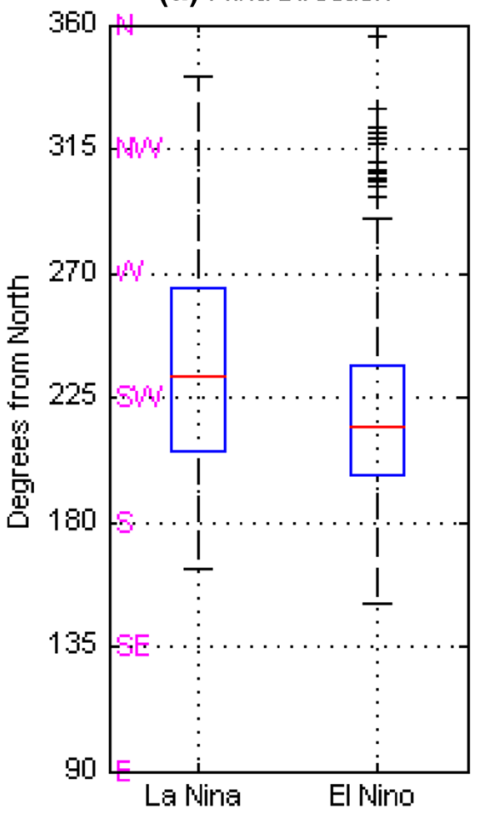

(b) Wind Speed

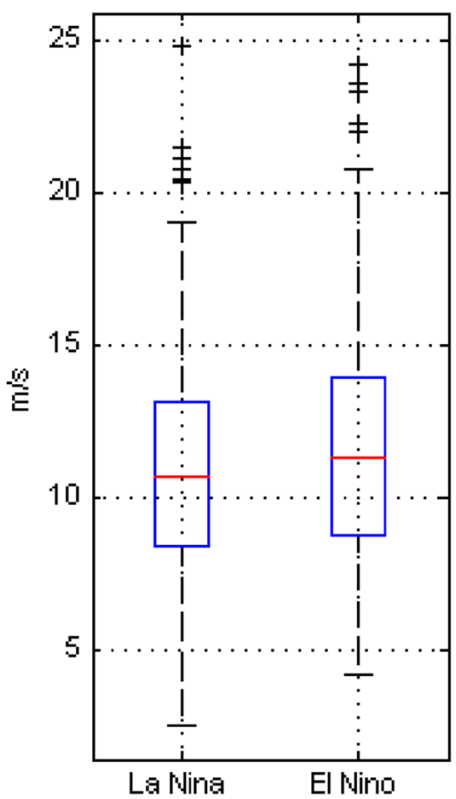

(c) $\mathrm{V} / \mathrm{T}$

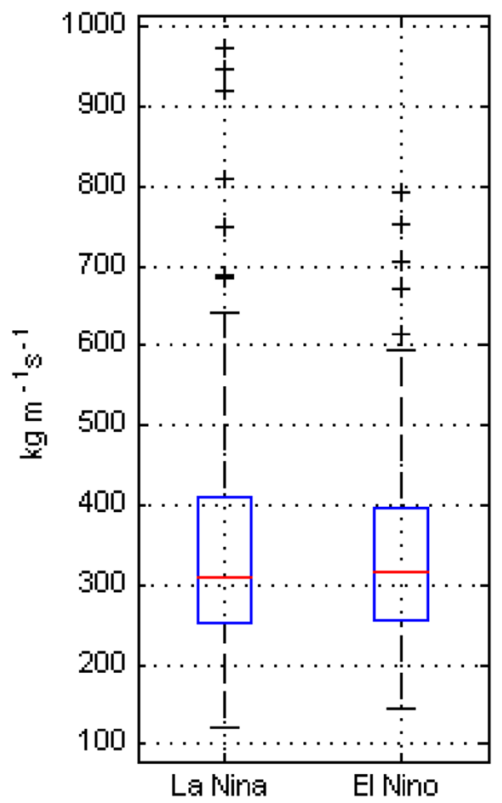

Fig. 5 The distribution of $\mathbf{a}$ wind direction, $\mathbf{b}$ wind speed, and $\mathbf{c}$ IVT at the coast at $40^{\circ} \mathrm{N}$ on the peak AR day stratified according to El Niño versus La Niña conditions. Only wind direction shows a signifi- cant ENSO effect ( $t$ test for unequal means, 95\% confidence). El Niño and La Niña conditions are defined as days when the Nino 3.4 index was above or below 0.5 , respectively

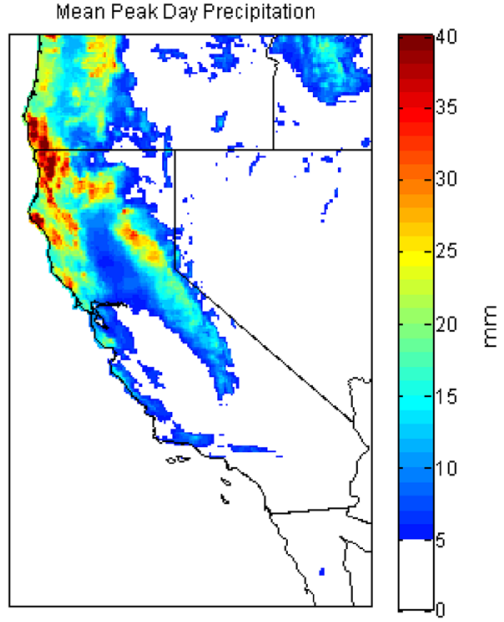

Fig. 6 Average precipitation observed at the AR peak. This represents the average over all nine AR types

shows the mean peak-day precipitation associated with the different types of ARs. From Figure S3 there is not a clear winner in terms of the amount of precipitation received over the domain. However, there are some important spatial differences. The spatial differences are better visualized in the anomaly maps given in Fig. 7. From this figure, we see that in general as we move from left to right (e.g. compare Types 1,4 , and 7 with Types 3, 6, and 9) precipitation increases to the north of California along the
Oregon coast, and decreases along the California coast and in the Sierras. As we move from top to bottom (e.g. compare Types 1-3 with Types 7-9) there is generally less precipitation in California. Recalling Fig. 3, the differences between the left nodes and the right nodes are primarily associated with the phase of ENSO/PDO, so we see from Fig. 7 that ARs occurring during El Niño (left nodes) bring heavier precipitation to coastal California and the Sierras compared to La Niña cases (right nodes). La Niña, on the other hand, brings more precipitation to coastal Oregon.

Recalling again Figs. 2 and 3, the differences between the top and the bottom nodes are primarily associated with the phase of the regional climate modes. The top nodes (1-3) are characterized by high pressure over Alaska/Bering Sea, which is associated with the negative phase of the AO/WPO/ EPO and the bottom nodes (7-9) are characterized with low pressure over Alaska/Bering Sea associated with the positive phase of the AO/WPO/EPO. Figure 7 suggests that when the regional climate modes are in the negative phase, ARs bring more precipitation to California. In Fig. 8 we try to separate the roles of ENSO and the regional modes in modulating precipitation variability in California. The ENSO/PDO effect is identified by comparing precipitation associated with the left nodes versus the right nodes. The regional mode effect is identified by comparing precipitation associated with the top nodes versus the bottom nodes. Here we see that both El Niño (Fig. 8a) and the negative phase of the regional climate 
Fig. 7 Precipitation anomaly maps showing the average precipitation received on the peak AR day for each of the nine AR types minus the average shown in Fig. 6. Only values that are statistically significant are colored (90\% level using bootstrapping). The text framing the perimeter describes the states of ENSO and the regional climate modes, using the findings from Fig. 3 where the left (right) columns correspond to El Niño (La Niña) and the top (bottom) rows correspond to the negative (positive) phase of the regional climate modes (AO/EPO/WPO)

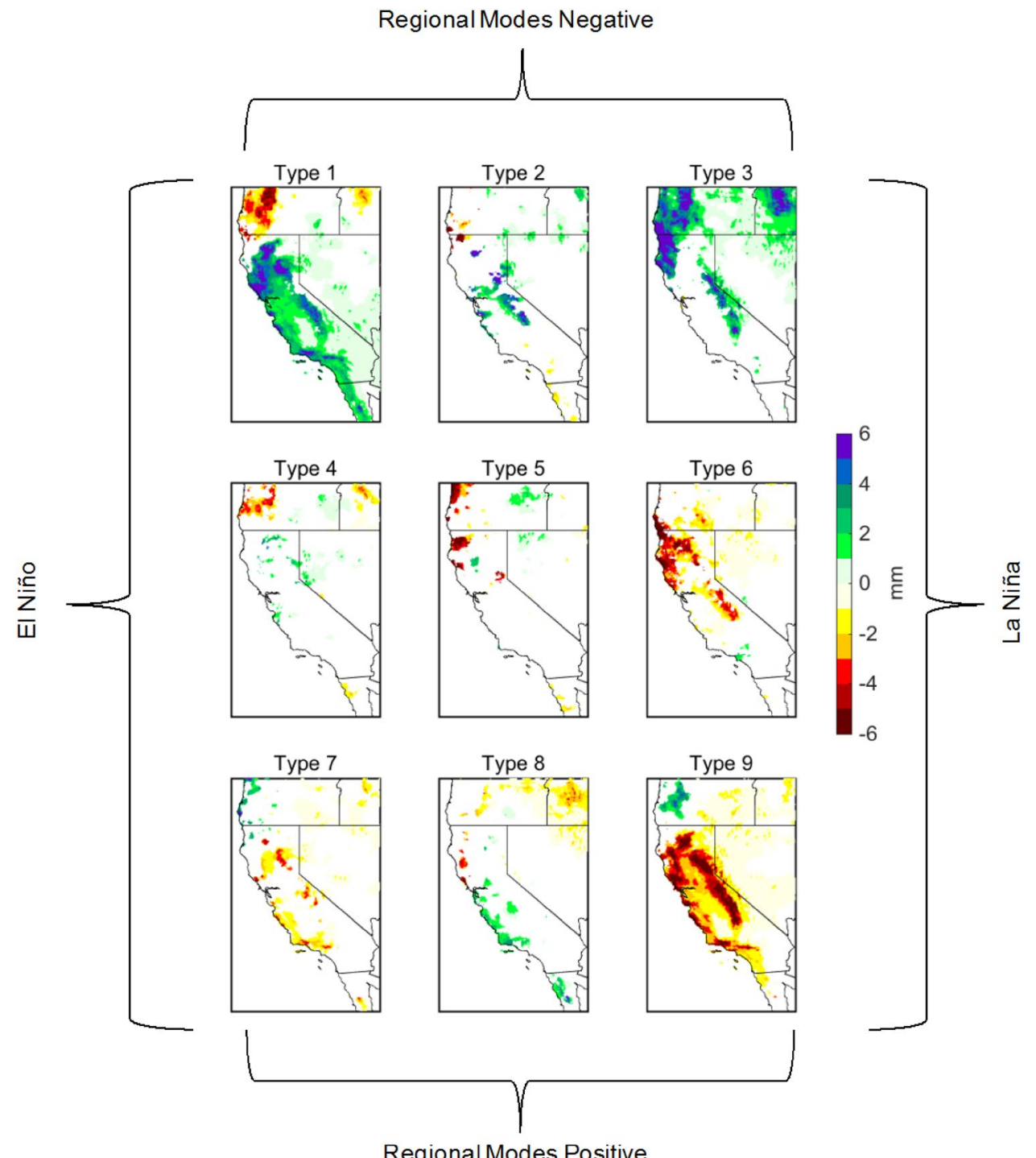

modes (Fig. 8b) are associated with heavier precipitation in California. However, the precipitation variability associated with different phases of the regional teleconnections is much greater than we observe for ENSO.

To better understand the role of the regional climate modes in modulating AR precipitation variability, we compare ARs that occurred when the regional modes were positive versus when they were negative. Figure 9a, b show the synoptic circulation (500-mb geopotential height anomalies) associated with the positive and negative phases of the regional modes, respectively, and Fig. 9c, d show the corresponding lower-level flow and IVT. In both the situations, regardless of the phase of the regional modes, flow is directed towards the US west coast along a low-pressure center located in the NE pacific. However, when the regional modes are negative (Fig. 9b, d), the low is positioned just offshore of $40^{\circ} \mathrm{N}$ and orientated in a southwest-to-northeast direction. This set-up is associated with a storm track that is displaced southward compared to that associated with ARs landfalling during the positive phase of the regional modes and with cyclonic flow around the closed-low offshore of Northern California. The ARs occurring when the regional modes are positive, in contrast, occur more to the north in a zonal orientation due the influence of the high-pressure center situated in the NW Pacific. The effect of the negative phase of the regional modes is similar to that of El Niño in terms of landfall orientation, which demonstrates how, subseasonally, the regional modes can act to reinforce or counter the effects of ENSO.

\subsection{Synoptic evolution of landfalling ARs and the role of ENSO}

Understanding the role of ENSO in modulating AR activity is important for extended range predictability, since seasonal precipitation predictions tend to primarily depend on 


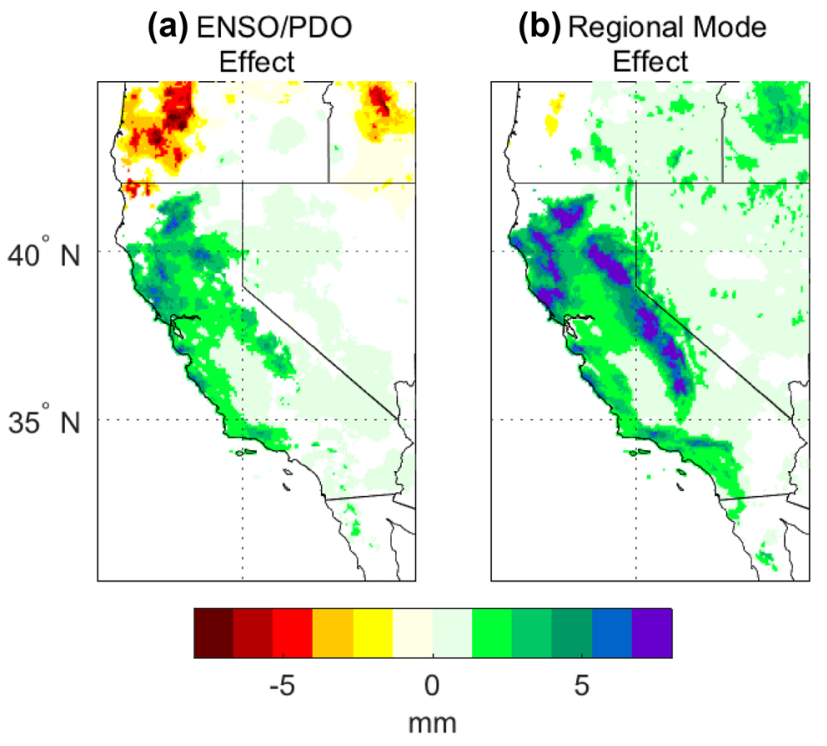

Fig. 8 Anomaly difference maps highlighting the effect of ENSO/ PDO and the regional modes in modulating precipitation variability. a The difference in precipitation between the left nodes (Types 1, 4, and 7) and the right nodes (Types 3, 6, and 9). Therefore, Panel a shows El Niño precipitation minus La Niña precipitation at the peak AR day. b Difference in precipitation between the top nodes (Types 1-3) and the bottom nodes (Types 7-9). Therefore, panel b shows precipitation occurring when the regional modes are negative minus precipitation occurring when they are positive. Heavier precipitation (green-blue-purple) in a means there is more precipitation during $\mathrm{El}$ Niño/PDO+. Heavier precipitation in $\mathbf{b}$ means there is more precipitation when the regional modes are negative. Only values that are statistically significant are colored (95\% level using bootstrapping) the state of ENSO, even-though twenty-first century ENSO excursions have mostly failed to deliver the expected precipitation anomalies to California. Northern California, around $40^{\circ} \mathrm{N}$, is at the fulcrum of the canonical ENSO influence on precipitation in which typically more (less) precipitation occurs to the north (south) during La Niña, with the opposite pattern during El Niño. The AR landfall probability at $40^{\circ} \mathrm{N}$ is close to climatology during El Niño and La Niña climate states, meaning ENSO has little influence on the likelihood of AR landfalls. During El Niño (La Niña) the probability of landfall is $23.6 \%$ (25.9\%), compared with random probability using bootstrapping $(24.0 \%, \mathrm{CI}=22.8-25.5, \alpha=0.05)$. Other studies have also shown little ENSO influence on AR landfall probability at this latitude (e.g. Payne and Magnusdottir 2014; Kim et al. 2017).

Although ENSO does not significantly affect the frequency of AR landfalls in Northern California, it does affect landfall characteristics and so, in this section, we investigate the role of ENSO in modulating the synoptic evolution of ARs, which can result in different orientations at landfall (Fig. 4), and ultimately different precipitation patterns (Figs. 7, 8). The 10-day evolution leading up to AR landfall is shown in Fig. 10 for AR types associated with El Niño (Types 1, 4, and 7) and in Fig. 11 for AR types associated with La Niña (Types 3, 7, and 9). From these figures, we see that the El Niño and La Niña cases are quite different. El Niño cases are characterized by a strong low in the North Pacific or Alaska/Bering Sea that is present out to 10 days, persisting to become the low-pressure component of the low-high pair at landfall. The preferred La Niña path, in contrast, features a North Pacific High that does not
Fig. 9 Composites showing the effect of the regional climate modes on circulation features and IVT during landfalling ARs at $40^{\circ} \mathrm{N}$. The left panels show ARs occurring when the regional modes were positive (a, c) and the right panels show ARs occurring when the regional modes were negative $(\mathbf{b}, \mathbf{d})$. The top panels $(\mathbf{a}, \mathbf{b})$ show composites of $500 \mathrm{mb}$ geopotential height anomalies and the lower panels $(\mathbf{c}, \mathbf{d})$ show composites of IVT (shaded) along with $850 \mathrm{mb}$ geopotential height anomalies (contours) and $850 \mathrm{mb}$ wind fields (vectors).

Here, to create conditions where the regional modes were positive or negative we composited all days when the AO, WPO, and EPO were in-phase and positive or negative, respectively (a) Positive Phase $500 \mathrm{mb} G \mathrm{PH}$

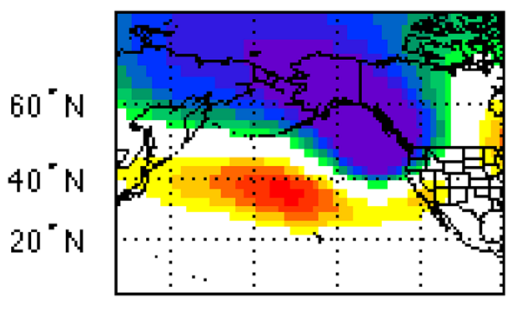

(c) Positive Phase $850 \mathrm{mb}$ circulation

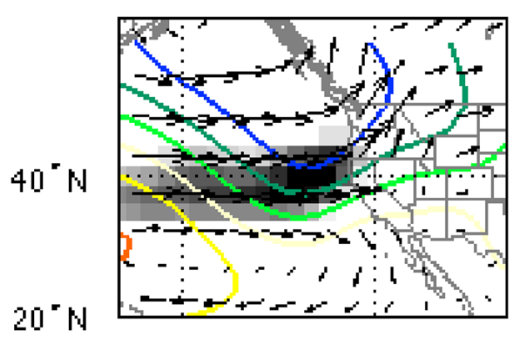

(b) Negative Phase $500 \mathrm{mb} \mathrm{GPH}$
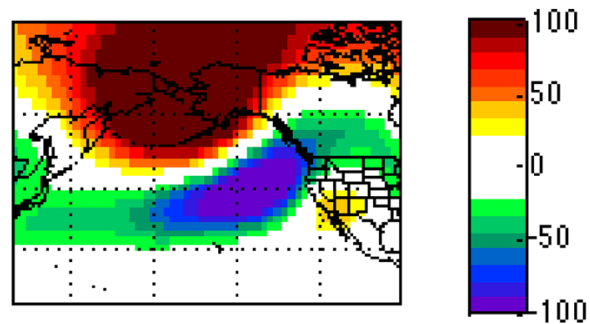

高

(d) Negative Phase

850 mb circulation

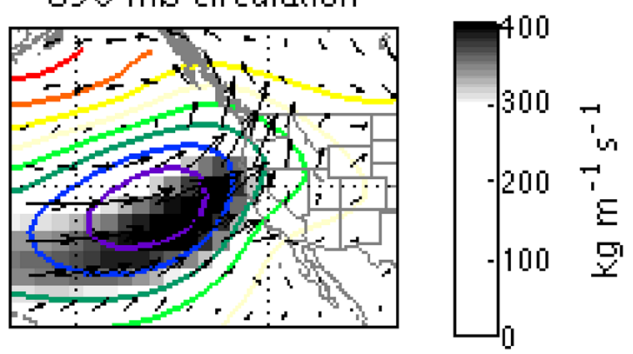


Fig. 10 The synoptic evolution of ARs of Type 1, 4, and 7, which are associated with El Niño. Shown here are composites of $500 \mathrm{mb}$ geopotential height anomalies starting from 10 days prior ( $\mathrm{t}-10)$ and leading up to the peak of a landfalling AR (t-0)
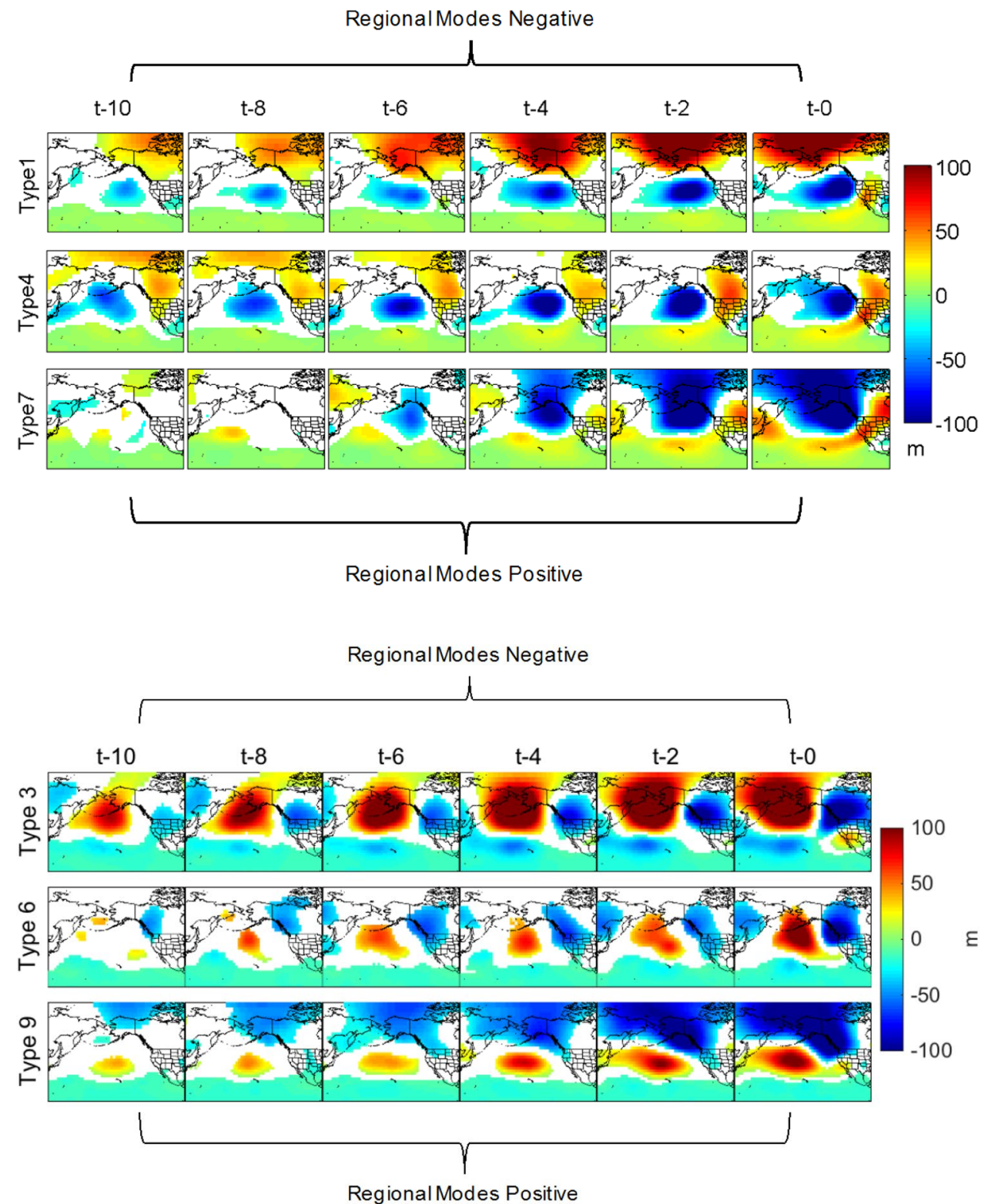

itself become a component of the low-high pair. Instead, the low-high pair forms to the east of the persistent North Pacific High. For the La Niña path, the role of the PNA is evident (i.e. compare circulation at $\mathrm{t}-0$ with the negative PNA composite in Figure S2). For the El Niño path, the anomalous Aleutian low appears to be the main influence.

Figure 12 shows the evolution of the different teleconnection indices out to 2-weeks before the AR peak for each of the AR types shown in Figs. 10 and 11. In general, the PNA starts out neutral or in-phase with ENSO and then becomes more strongly positive during El Niño or more strongly negative during La Niña. Changes in strength of the AO/WPO/ EPO are also observed around 10 days lead, but the direction of change is variable where in some cases they become more strongly negative (Types 1 and 3) and in others they become strongly positive (Types 7 and 9) and in others they remain relatively neutral (Types 4 and 6).

Figures 10, 11 and 12 demonstrate how the evolution of an AR depends on the climate state and the occurrence of an AR, and its orientation at landfall, reflects an interplay between climate modes operating at different timescales. Understanding these seasonal-to-subseasonal interactions seems key for extended range predictability. In the next section, we investigate these seasonal and subseasonal influences during the recent water year 2016-2017. 
Fig. 12 Composites of the six standardized (SD) teleconnection indices out to 14 days before AR peak. The circular filled markers indicates values significantly different from climatology $(\alpha=0.05$ using bootstrapping). The top row (Types 1, 4, and 7) are associated with El Niño and the bottom row (Types 3, 6, and 9) are associated with La Niña

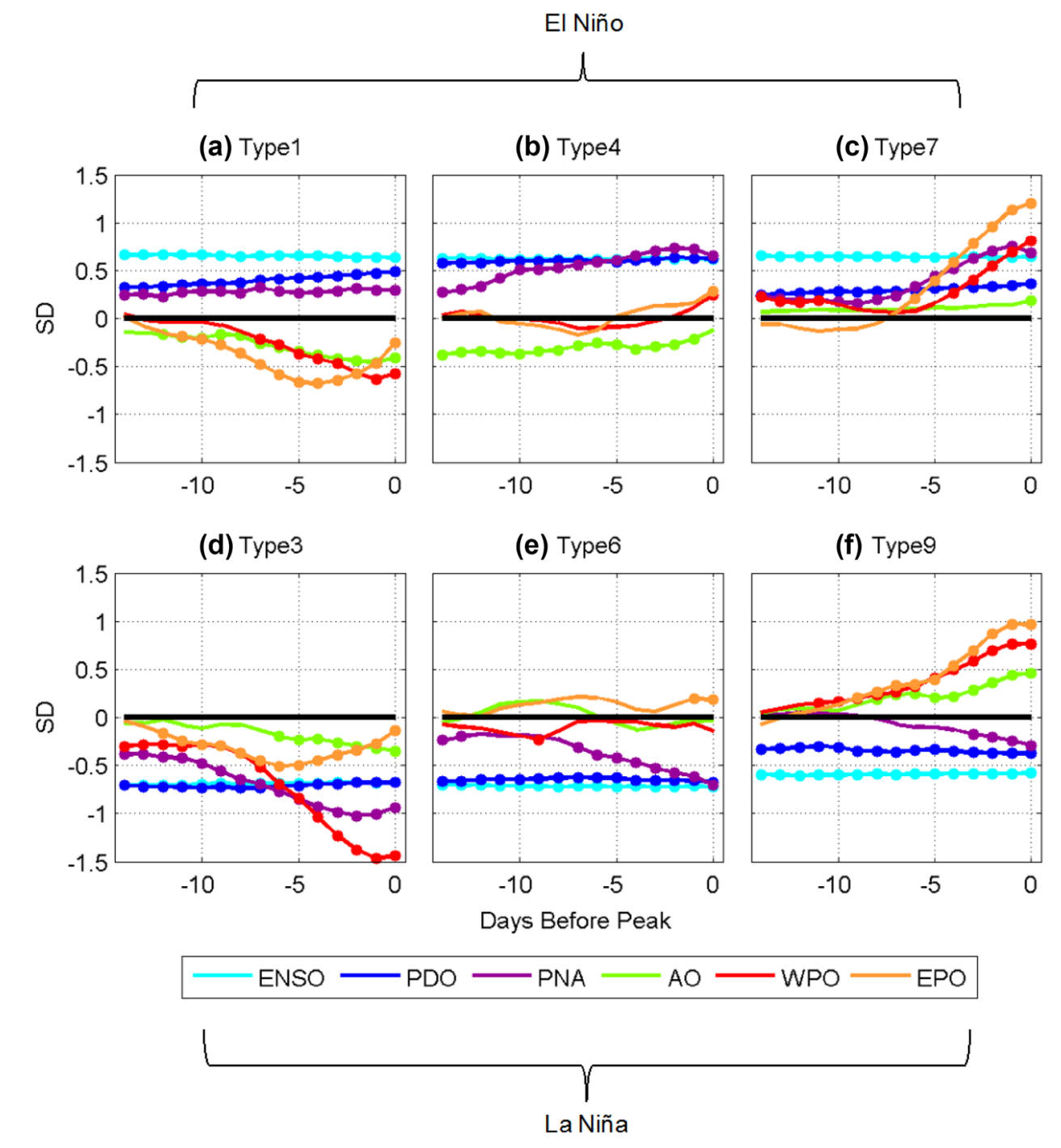

\section{Applications to the recent 2016-2017 water year}

The 2016-2017 water year was unusual in many ways. California entered the season in the midst of a historic drought and, following an extremely active AR season, was declared drought-free (e.g. Los Angeles Times 2017). The early part of the season was very wet but because many of the early storms were warm, California was still at a snow deficit as of January 1 (Harpold et al. 2017). By March, however, snowfall in the Sierra was $164 \%$ of normal, more than the previous 4 years combined (California Department of Water Resources 2017). While the outcome was a relief to many, the water year was challenging, particularly for water resource managers. In February, following a spate of mostly AR storms, the emergency spillway at Oroville Dam in Northern California overflowed due to rising lake levels resulting in the evacuation of 180,000 people (San Jose Mercury News 2017). In this Section, we investigate AR activity in Northern California during this drought-busting season.

Figure 13a shows AR activity at $40^{\circ} \mathrm{N}$ during Nov-Feb where we see that several ARs made landfall. We determined the AR type by mapping observed 500-mb height fields from each day during WY'17 onto the SOMs shown in Fig. 2, and assigning each day to the best fitting node. Types 1-3 and Types 7-9 were grouped together because the fit was generally similar within these groups due to the similarity in circulation features within the top-row SOMs and bottomrow SOMs (Fig. 2).

We see from Fig. 13a that the ARs generally alternated between Type 1-3 and Type 7-9. The Type 1-3 ARs dominated in the sense that they were especially intense and longlasting. Recall that Type 1-3 ARs occur when the regional climate modes are negative, and during these conditions the AR track tends to be pushed farther south and landfall occurs in a southwesterly orientation, thereby bringing more precipitation to California and particularly to the Sierra Nevada. 


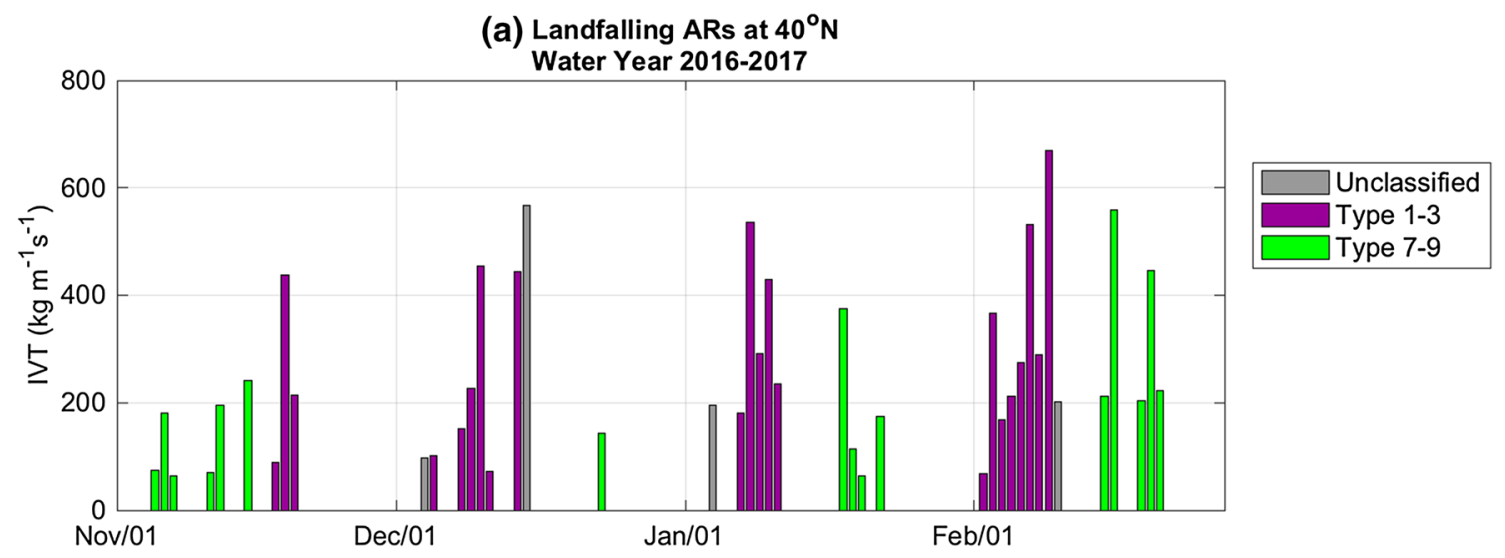

(b) Standardized Teleconnection Indices Water Year 2016-2017

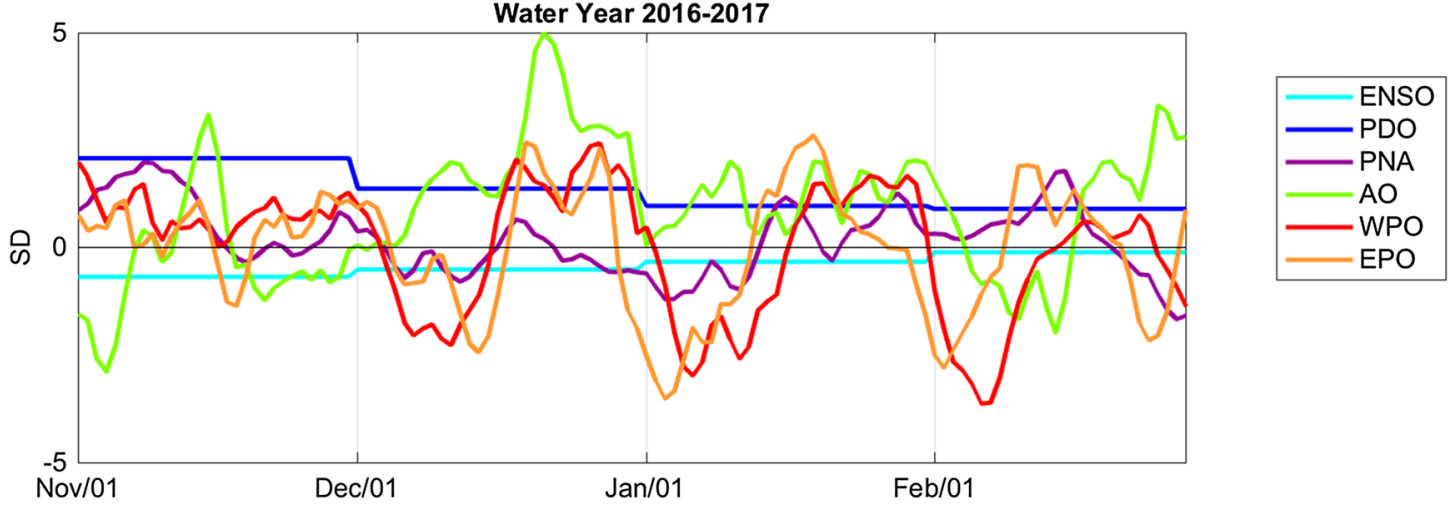

Fig. 13 Observations of the 2016-2017 water year showing a IVT associated with landfalling ARs at $40^{\circ} \mathrm{N}$, color coded by AR Type and $\mathbf{b}$ the seasonal evolution of the teleconnection Indices. The AR type was determined by mapping observations for each day onto the SOMs shown in Fig. 2 and assigning each day to the best fitting node.

Figure 14a shows circulation composites of the Type 1-3 ARs during WY'17 and, as expected, we see the characteristic high pressure centered over Alaska/Bering Sea with the low-high pair positioned off the coast of the western US. Figure $13 \mathrm{~b}$ shows the phase and strength of the different teleconnection indices. From this figure, we see that when Type 1-3 ARs were making landfall, the high-pressure conditions over Alaska/Bering Sea were associated with the joint negative phase of the WPO and EPO.

By contrast, Type 7-9 ARs occurred during strong Aleutian low conditions and with low pressure extending over Alaska (Fig. 14b). A comparison of IVT fields during Type 1-3 versus Type 7-9 ARs shows that, as expected from the historical analysis, the AR track extends farther south during the Type 1-3 ARs and more moisture is transported into California.

The unusually wet conditions in Northern California during the winter of 2016/2017 appear to be at least partly due to the persistence of Type 1-3 events, which represent the
Spatial correlation between the observed field and corresponding SOM was required to be above 0.3 or the AR was left unclassified. Types 1-3 and Types 7-9 were grouped together. In panel (a), days showing AR IVT values below $250 \mathrm{~kg} \mathrm{~m}^{-1} \mathrm{~s}^{-1}$ imply that the AR was present for only part of the calendar day (see Sect. 2.2)

type of ARs associated with heavy rainfall in California, and which occurred repeatedly during the season. The average duration of a landfalling $\mathrm{AR}$ at $40^{\circ} \mathrm{N}$ is 2.5 days. During WY' 17 , there were three Type 1-3 ARs that were especially long-lasting. A 4-day event on Dec 8-11, a 5-day event on Jan 7-11, and a nearly unprecedented 8-day event on Feb 2-9. An 8-day AR event is very rare, representing only about $3 \%$ of ARs making landfall at this location. Additionally, the IVT content associated with these storms was extremely high. For the California coast in general, the IVT associated with landfalling ARs during WY'17 reached record magnitudes (GSR'17). At $40^{\circ} \mathrm{N}$, the peak IVT during the Feb 2-9 event exceeded the historical 98th percentile, so not only was this event unusually long, it was also extremely intense in terms of vapor transport. It was just after this 8-day event in February, which followed a series of other wet events, that overflow at Oroville dam occurred leading to large-scale evacuations. The storms of Jan 8-10 and Feb 7-9 
Fig. 14 Composites of 500mb geopotential height anomalies for days when ARs of Type 1-3 (a) or Types 7-9 (b) were making landfall at $40^{\circ} \mathrm{N}$ during the 2016-2017 water year. Difference in IVT fields for the two types of events are shown in panel (c), displayed as average IVT during Type 1-3 events minus average IVT during Type 7-9 events (a) Type 1-3 events

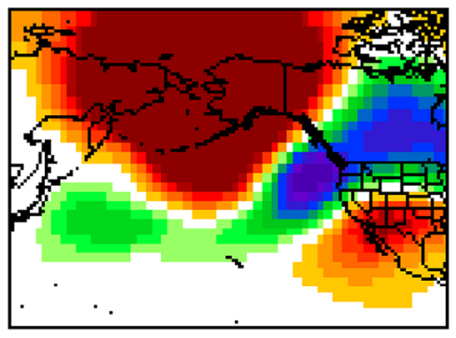

(b) Type $7-9$ events

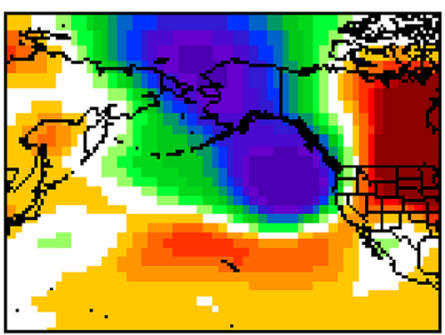

(c) Difference in IV'T

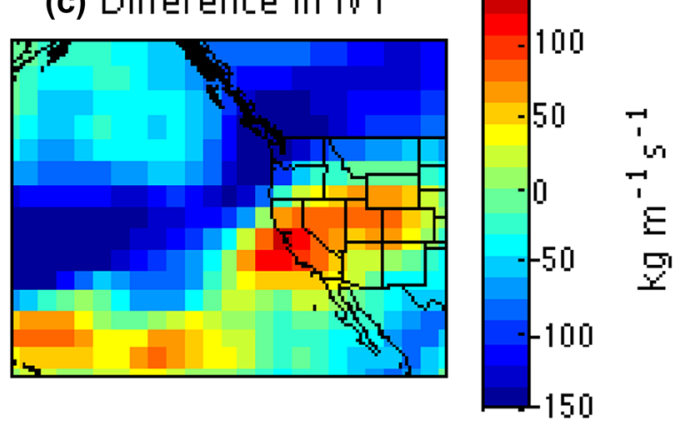

were particularly wet for California, which together brought almost a quarter of a normal year's annual precipitation in just 6 days.

\section{Summary and discussion}

We analyzed over six decades of atmospheric rivers making landfall in Northern California. We observed several different types of ARs characterized by differences in atmospheric circulation patterns that yield different pathways to ARs impacting the California coast at $40^{\circ} \mathrm{N}$. The commonality among all ARs is the requisite low-high pair positioned along the US West Coast. However, there are important differences between the various types of ARs, which are modulated by the climate state and regional teleconnection patterns. These differences were found to have important implications for precipitation variability. In general, the phase of ENSO and the PDO appear to modulate the IVT direction at landfall and landfall-evolution. During El Niño/ $\mathrm{PDO}+$ the preferred landfall orientation is southerly-southwesterly while during La Niña/PDO- a more westerly flow is observed. This is in agreement with previous work (Ryoo et al. 2013; Favre and Gershunov 2006; Kim and Alexander 2015; Kim et al. 2017) noting more cyclonic (anticyclonic) systems along California during El Niño (La Niña) excursions. These results also support the work of Kim et al. (2017) who examined AR activity along the US west coast during different phases of ENSO and found important ENSO influence for vapor transport and storm intensity, but little influence on AR landfall probability in Northern California.

We investigated the role of regional climate modes in modulating AR activity in Northern California. The negative phase of the AO/WPO/EPO is associated with more precipitation in California, which we attribute to circulation features that affect the AR track and orientation at landfall. In general, a more southwesterly flow is observed when the regional modes are negative and a more westerly flow occurs when they are positive. It follows that more precipitation occurs in California during El Niño and/or when the regional modes are negative. An analysis comparing effect of ENSO versus the regional climate modes in modulating precipitation in California showed the regional modes to be more influential than ENSO in modulating AR precipitation, which demonstrates how, subseasonally, the regional modes can act to reinforce or counter the effects of ENSO.

As discussed above in the Introduction, there is a body of work that has shown the importance of landfall orientation in determining inland penetration of water vapor and the amount of precipitation associated with a landfalling AR. Hu et al. (2017) in particular demonstrated that the heaviest precipitation tends to occur when vapor transport is aligned perpendicular to the local terrain barrier. They summarized that from about $40^{\circ} \mathrm{N}$ and northward into Oregon, the Coast Ranges are positioned in a north-south orientation while the Cascades are NNE-SSW. South of 
about $40^{\circ} \mathrm{N}$ and spanning the rest of California, the Coast Ranges are positioned northwest-to-southeast, as are the Sierra Nevada. This explains the spatial differences we observed in this study associated with different phases of ENSO and also with the different phases of the regional climate modes. During La Niña, ARs tend to make landfall in a westerly direction, with an impingement angle that is perpendicular to the topography in the very northern part of California and in coastal Oregon, and this is in fact where we see more precipitation occur during La Niña. On the other hand, during El Niño, ARs tend to make landfall in a southwesterly direction, roughly perpendicular to the northwest-to-southeast orientated topography in California, and hence we observe more precipitation in the California Coastal Ranges and Sierra Nevada during El Niño. Hu et al. (2017) showed that in California, ARs with a cyclonic orientation bring more precipitation and our results are in agreement with that work. These results also reinforce the work of GSR' 17, which found stronger southerly IVT and enhanced California precipitation during the positive phase of the PDO. Seasonal AR frequency and total intensity are, however, not affected by ENSO as had been described by GSR' 17 .

These results are useful for understanding the different ways an AR can impact Northern California at $40^{\circ} \mathrm{N}$. This location is important for water resources in California and is also the most active location for ARs, in terms of intensity, along the US west coast (GSR'17). However, the results may not be generalizable for other locations (e.g. those away from $\mathrm{NCal} /$ Oregon) as the roles of ENSO, PDO, and the regional climate modes could be different.

A strength of this analysis is that it provides insights into the interplay between climate modes acting on land falling ARs at different timescales. We showed that the likelihood of certain trajectories developing is conditional on the climate state, particularly ENSO and the PDO. These trajectories involve persistent features in the Pacific identified out to at least 10 days lead, which ultimately play a role in setting up the low-high pair off the coast of California that is a requisite for a landfalling AR. These features are different for La Niña versus El Niño states, and understanding these pathways better could improve predictions in the extended range, i.e. weeks 3-4.

Seasonal precipitation forecasts for California have performed poorly in recent years. This includes the most recent water year, which occurred during a weak La Niña and saw copious amounts of precipitation that was not expected. Recent work suggests that traditional predictors like ENSO may do well explaining seasonal IVT along the US west coast, but do not necessarily explain IVT levels associated with landfalling ARs (GSR'17). The findings from this paper support this idea by highlighting the importance of regional teleconnection patterns. This work suggests that these regional modes may play a stronger role in precipitation variability than the traditional climate modes typically used in seasonal forecasts. We found that it is the interaction between the climate state and regional climate modes that largely determines the pathway to an AR landfall. Therefore, extended range predictions could benefit by conditioning forecasts on the climate state. This methodology could also be applied to multi-decadal retrospective reforecast data, which would help to quantify the ability of dynamical models to represent these modes of AR influence and evaluate their S2S predictability.

Acknowledegements This work was funded by Department of the Interior via the Bureau of Reclamation (USBR-R15AC00003, Seasonal and extended-range predictability of atmospheric rivers and their associated precipitation) and by the California Department of Water Resources (4600010378 UCOP2-11, Development of Seasonal Outlooks for Atmospheric rivers). We also appreciate support from Climate Education Partners, a National Science Foundation funded project DUE-1239797. This study also contributes to DOI's Southwest Climate Science Center and NOAA's California and Nevada Applications Program award NA11OAR43101. We thank two anonymous reviewers for their helpful comments during the review process.

Open Access This article is distributed under the terms of the Creative Commons Attribution 4.0 International License (http://creativeco mmons.org/licenses/by/4.0/), which permits unrestricted use, distribution, and reproduction in any medium, provided you give appropriate credit to the original author(s) and the source, provide a link to the Creative Commons license, and indicate if changes were made.

\section{References}

Andrews AD, Antweiller RC, Neiman PJ, Ralph FM (2004) Influence of ENSO on flood frequency along the California Coast. J Clim 17:337-348

Barnston AG, Livezey RE (1987) Classification, seasonality and persistence of low-frequency atmospheric circulation patterns. Mon Weather Rev 115:1083-1126. https://doi.org/10.1175/15200493(1987)115\%3C1083:CSAPOL\%3E2.0.CO;2

Bond NA, Cronin MF, Freeland H, Mantua N (2015) Causes and impacts of the 2014 warm anomaly in the NE Pacific. Geophys Res Lett 42:3414-3420. https://doi.org/10.1002/2015GL063306

Department of Water Resources (2017) Snowpack's water content remains far above average. https://water.ca.gov/-/media/DWRWebsite/Web-Pages/News-Releases/Files/2017-News-Relea ses/033017-News-Release_snow_survey_release-april2017.pdf. Accessed 25 July 2017

Dettinger MD (2013) Atmospheric rivers as Drought Busters on the U.S. West Coast. J Hydrometeorol 14:1721-1732. https://doi. org/10.1175/JHM-D-13-02.1.

Dettinger MD, Ralph FM, Das T, Neiman PJ, Cayan DR (2011) Atmospheric rivers, floods, and the water resources of California. Water 3:445-478. https://doi.org/10.3390/w3020445.

Diaz HF, Wahl ER (2015) Recent California water year precipitation deficits: a 440-year perspective. J Clim 28:4637-4652

Favre A, Gershunov A (2006) Extra-tropical cyclonic/anticyclonic activity in North-Eastern Pacific and air temperature extremes in Western North America. Clim Dyn 26:617-629. https://doi. org/10.1007/s00382-005-0101-9 
Feldstein SB (2000) The timescale, power spectra, and climate noise properties of teleconnection patterns. J Clim 13:4430-4440. https://doi.org/10.1175/1520-0442(2000)013\%3C4430:TTPSA C\%3E2.0.CO;2

Gershunov A (1998) ENSO influence on intraseasonal extreme rainfall and temperature frequencies in the contiguous US: implications for long-range predictability. J Clim 11:3192-3203

Gershunov A, Cayan DR (2003) Heavy Daily precipitation frequency over the contiguous United States: sources of climatic variability and seasonal predictability. J Clim 16:2752-2765

Gershunov A, Shulgina T, Ralph FM, Lavers D, Rutz JJ (2017) Assessing the climate-scale variability of atmospheric rivers affecting the west coast of North America, Geophys Res Lett. https://doi. org/10.1002/2017GRL074175

Guan B, Waliser DE (2015) Detection of atmospheric rivers: evaluation and application of an algorithm for global studies. J Geophys Res Atmos 120:12514-12535. https://doi.org/10.1002/2015JD024257

Guan B, Molotch NP, Waliser DE, Fetzer EJ, Neiman PJ (2013) The 2010/2011 snow season in California's Sierra Nevada: role of atmospheric rivers and modes of large-scale variability. Water Resour Res 49:6731-6743. https://doi.org/10.1002/wrcr.20537

Harpold AA, Dettinger MD, Rajagopal S (2017) EOS 98:15-17. https ://doi.org/10.1029/2017EO068775

Hu H, Dominguez F, Wang Z, Lavers DA, Zhang G, Ralph F (2017) Linking atmospheric river hydrological impacts on the U.S. West coast to rossby wave breaking. J Clim 30:3381-3399. https://doi. org/10.1175/JCLI-D-16-0386.1

Kalnay E et al (1996) The NCEP/NCAR 40-year reanalysis project. Bull Am Meteorol Soc 77(3):437-471

Kim H-M, Alexander MA (2015) ENSO's modulation of water vapor transport over the Pacific-North American region. J Clim 28:3846-3856

Kim HM, Zhou Y, Alexander MA (2017) Changes in atmospheric rivers and moisture transport over the Northeast Pacific and western North America in response to ENSO diversity. Clim Dyn. https:// doi.org/10.1007/s00382-017-35989

Konrad CP, Dettinger MD (2017) Flood runoff in relation to water vapor transport by atmospheric rivers over the western United States, 1949-2015. Geophys Res Lett. https://doi. org/10.1002/2017GL075399

Leung LR, Qian Y (2009) Atmospheric rivers induced heavy precipitation and flooding in the western U.S. simulated by the WRF regional climate model. Geophys Res Lett 36:L03820. https://doi. org/10.1029/2008GL036445

Livneh B, Rosenberg EA, Lin C, Nijssen B, Mishra V, Andreadis KM, Maurer EP, Lettenmaier DP (2013) A long-term hydrologically based dataset of land surface fluxes and states for the conterminous united states: update and extensions. J Clim 26:9384-9392
Los Angeles Times (2017) Gov. Brown declares California drought emergency is over

National Climatic Date Center (2009) Data documentation for data set 3200 (DSI-3200): surface land daily cooperative summary of the day, Report Asheville, NC. http://www.ncdc.noaa.gov/pub/data/ documentlibrary/tddoc/td3200.pdf

Neiman PJ, Ralph FM, Wick GA, Lundquist JD, Dettinger MD (2008) Meteorological characteristics and overland precipitation impacts of atmospheric rivers affecting the West Coast of North America based on eight years of SSM/I satellite observations. J Hydrometeorol 9:22-47

Payne AE, Magnusdottir G (2014) Dynamics of landfalling atmospheric rivers over the North Pacific in 30 years of MERRA reanalysis. J Clim 27:7133-7150

Polade SD, Pierce DW, Cayan DR, Gershunov A, Dettinger MD (2014) The key role of dry days in changing regional climate and precipitation regimes. Sci Rep. https://doi.org/10.1038/srep04364

Polade SD, Gershunov A, Cayan DR, Dettinger MD, Pierce DW (2017) Precipitation in a warming world: assessing projected hydro-climate of California and other Mediterranean climate regions. Nat Sci Rep 7:10783. https://doi.org/10.1038/s41598-017-11285-y

Ralph FM, Neiman PJ, Kingsmill DE, Ola P, Persson G, White AL, Strem ET, Andrews ED, Antweiller RC (2003) The impact of prominent rain shadow on flooding in California's Santa Cruz Mountains: a CALJET case study and sensitivity to the ENSO cycle. J Hydrometrol 4:1243-1264

Ralph FM, Neiman PJ, Wick GA, Gutman SI, Dettinger MD, Cayan DR, White AB (2006) Flooding on California's Russian River: Role of atmospheric rivers. Geophys Res Lett 33:L13801. https ://doi.org/10.1029/2006GL026689

Reusch DB, Alley RB, Hewitson BC (2005) Relative performance of self-organizing maps and principal component analysis in pattern extraction from synthetic climatological data. Polar Geogrph 29(3):188-212. https://doi.org/10.1080/789610199

Ryoo J, Kaspi Y, Waugh DW, Kiladis GN, Waliser DE, Fetzer EJ, Kim J (2013) Impact of Rossby wave breaking on U.S. West Coast winter precipitation during ENSO events. J Clim 26:6360-6382. https://doi.org/10.1175/JCLI-D-12-00297.1.

San Jose Mercury News (2017) Oroville Dam Timeline: 100 days of drama

Swain DL, Langenbrunner B, Neelin JD, Hall A (2018) Increasing precipitation volatility in twenty-first-century California. Nat Clim Change 8(5):427-433

Swales D, Alexander M, Hughes M (2016) Examining moisture pathways and extreme precipitation in the U.S. Intermountain West using self-organizing maps. Geophys Res Lett 43(4):1727-1735 